\title{
Economic Damage Assessment of Coastal Development using Dynamic Bioeconomic Model
}

\author{
+ Tae-Goun Kim \\ † Assistant Professor, Division of Maritime Transportation Science, Korea Maritime University, Busan 606-791, Korea
}

\begin{abstract}
This article analyzes the interdependency between nonrenewable marine sand resources and renewable fishery resources by the developed dynamic bioeconomic model. The developed bioeconomic model is applied to a case study of efficient sustainable management for marine sand mining, which adversely affects a valuable blue crab fishery and its habitat in Korea. The socially-efficient extraction plan for marine sand and the time-variant environmental external costs to society in terms of diminished harvest rate of blue crab are determined. To take into account long-term effects from destroyed fishery habitat, a Beverton-Holt age structure model is integrated into the bioeconomic model. The illustrative results reveal that the efficient sand extraction plan is dynamically constrained by the stock size of the blue crab fishery over time. Thus, the dynamic environmental external cost is more realistic resource policy option than the classical fixed external cost for determining socially optimal extraction plans. Additionally, the economic value of bottom habitat, which supports the on- and off-site commercial blue crab fishery is estimated. The empirical results are interpreted with emphasis on guidelines for management policy for marine sand mining.
\end{abstract}

Key words : Marine sand mining, Interdependency, Bioeconmic model, Dynamic external costs, Habitat value

\section{Introduction}

The marine and coastal development impacts on inter-related other natural resources and environments are worldwide issues (Freeman, 2003; Swallow, 1990, 1994; Vita, 2006). Many countries have developed marine and coastal exhaustible resources such as marine sand and gravel, and oil and gas, or have converted wetlands and estuaries to agricultural, industrial, and/or urban areas. These coastal development activities adversely affect the services provided by renewable resources, especially commercial and recreational fishery resources and their habitats (Barbier, 2007; Barbier et al., 2002; Kim, 2009; Kim and Grigalunas, 2009; Kim et al., 2008; Swallow 1990, 1994, 1996; Vita, 2006; Upton and Sutinen, 2005). However, the degradation of renewable fishery resources, especially in many developing countries, has been accepted as a necessary consequence of developing valuable exhaustible resources, with some countries in effect assigning a zero value to these renewable resources (Barbier, 2007; Barbier et al., 2002; Cho, 2006; Kim et al., 2008).

Hotelling-type exhaustible resource theory (Hoel 1978; Hotelling, 1931; Krautkraemer, 1998; Pindyck, 1978; Schulze, 1974) provides an optimal extraction plan for exhaustible resources but ignores the presence of externalities on renewable resources (Swallow 1990, 1994, 1996; Vita, 2006). To consider an environmental externality, Schulze (1974) modified the traditional Hotelling rule by internalizing environmental damages in an extraction model. In his article, an optimal dynamic Pigovian tax depending on current stock size of the affected resources was introduced to include the "irreversible" damages to forest lands, assessed as the economic losses in recreation and scenic benefits from the mining. His results show that if the externalities on the affected renewable resources were misestimated, the optimal management plan for the exhaustible resources would be altered substantially. Several valuable papers in the environmental and resource economics literature investigate the linkage between nonrenewable resource development and renewable fishery and its habitat damages. Barbier (2007) and Barbier et al. (2002) estimated welfare impacts as the environmental costs from converting wetlands or mangroves (as nonrenewable resources) to aquaculture areas using static and dynamic bioeconomic models and then estimated the marginal foregone value of irreversibly developed wetlands/mangroves. These studies, however, did not assess the net welfare impacts, taking into account the tradeoff between the amount of development and conservation of mangroves or wetlands.

\footnotetext{
† Corresponding author, teddykim48@hhu.ac.kr 051)410-4437
} 
To investigate the general tradeoff issues on coastal development, Swallow (1990, 1994, 1996) developed bio-economic models for fishery-habitat linkages with coastal zone development by explicitly considering both exhaustible and renewable resources in a net-benefit maximization model. However, authors of the former studies used an econometric approach to estimate economic values of preserving habitats based on the "irreversibility" on quantity and/or quality (i.e., decrease in a fixed carrying capacity for fish species) of the affected habitats. Hence, their models do not apply to cases where the harmed habitats would recover after the coastal development ceases, like the marine sand and gravel mining case considered in this article. Moreover, in the majority of cases, adequate historical data do not exist for an econometric estimation.

This article seeks to extend the earlier renewableand-nonrenewable resource management analysis (e.g. Barbier, 2007; Swallow, 1990, 1994, 1996) using the case of marine sand development with externalities on the commercial blue crab fishery in Ongjin District, Korea. The main objectives of this article are 1) to develop an explicit bio-economic simulation model taking into account linkages between exhaustible and renewable resources including dynamic external costs on the commercial fishery from marine sand development; 2) to estimate the bottom habitat value for renewable fishery resources allowing dynamic reversibility of the affected bottom habitats; 3) to apply this interdependent resource-uses framework to the case of marine sand resources development in Ongjin district,
Korea; and 4) to suggest an efficient management plan for both exhaustible marine sand resources and renewable commercial fishery resources.

The blue crab is used as a representative, vulnerable commercial fishery in the Ongjin District because the blue crab is a bottom-dwelling species which is directly exposed to marine sand mining, and moreover, it accounts for fully $62 \%$ of total fishery revenue in Ongjin District. Most blue crab is caught by gill net fishing in Ongjin District (MOMAF, 2003; NFRDI, 2004). The other main reason for selection of blue crab is that it is the only species with data available for the analysis needed.

\section{Background of study area}

Since 1992, marine sand mining activities have been conducted in Korea and marine sand become second primary source for total Korea sand supply after 2000. For the marine sand supply, Ongjin District was a main sand mining area up to 2003, which is located within metro area of the city of Incheon (Fig. 1). Ongjin District collectively accounts for about $60 \%$ of the marine sand supply in Korea and cumulative quantity of marine sand extracted is about 0.2 billion $\mathrm{m}^{3}$ in Ongjin District only (Kim et al., 2008; Korea Aggregate Association, 2002).

Until recently, large quantity of marine sand resources were freely extracted to satisfy the demand of the Korean construction industry (as input for concrete) for the national development plan without any regard to environmental damages. At the beginning of 2000,

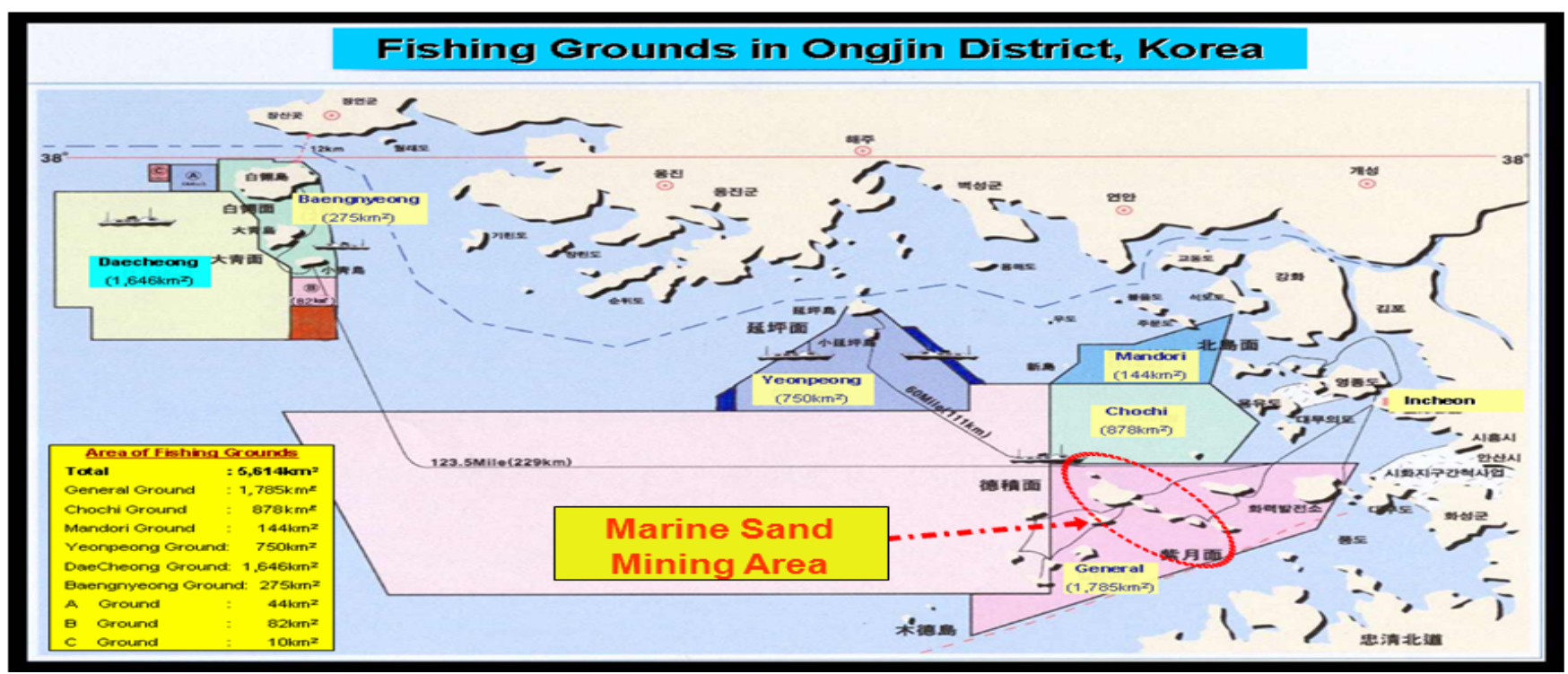

Fig. 1 Marine sand mining area and commercial fishing ground in Ongjin District 
environmental damages from the mining were raised as a concern, and then it became very delicate issue between local commercial fishermen and sand mining operators in the Ongjin District. The former argued the sand mining had severely damaged the commercial fishery resources, while the later strongly claimed there was no definite evidence of adverse effects on the environment from marine sand mining (Cho, 2006; Kim et al., 2008; Korea Aggregate Association, 2002).

Although several other factors including over-fishing could affect fishery stock size, marine sand mining has been reported as the primary factor by Korean scientists. The average annual catch in the post mining period (1994 2001) was 38\% lower as compared with the pre mining period (1979 1993). Several scientific studies showed that the fishery populations on the mining sites were significantly different with populations in adjacent areas (Cho, 2006; Cho and Chang, 2003; Kim and Grigalunas, 2009; Kim et al., 2008; Korea Aggregate Association, 2002).

Unfortunately, there has been limited research on the direct cause-and-effect relationship between sand mining and damages on the marine environment in Korea. Most research studies were biological and physical studies only, so that the results were qualitative damages assessment, not quantitative, although there were a few economic studies which estimated the external costs of mining on commercial fisheries (Kim, 2009; Kim et al., 2008). Moreover, the Korean government leans toward a pro-development policy for economic growth. So every 5 years a marine sand extraction plan was based on the supply for aggregate-and-construction industry. The limited information and unbalanced government policy, and concerns expressed by fishing interests, eventually led to a moratorium on issuing mining permits in 2005, Ongjin District (Kim, 2009; Kim et al., 2008).

However, a moratorium is not likely an acceptable long-term solution for the marine sand resource management, given the national development plan in Korea. A conceptually sound and empirically robust economic studies might suggest the efficient use of exhaustible marine sand resources taking into account the potential trade-offs between extraction of marine sand and preservation of the marine environment, here the commercial fishery.

Recent studies by Kim and Grigalunas (2009) and Kim et al. (2008) have estimated the potential external costs on the commercial fisheries, taking into account long-term habitat loss as the primary affected renewable resources from marine sand mining. These initial studies considered the reversibility (or recovery) of the damaged bottom habitats, static marginal external costs were estimated based on the current stock size only. While their results were a first attempt to quantify external costs for marine sand mining, they did not attempt to model the efficient extraction plans for marine sand which internalize the dynamic environmental costs on renewable fishery resources.

\section{Joint extraction model of Nonrenewable and Renewable resources}

The joint management model for marine sand resources and commercial fisheries is derived from two fundamental theories on nonrenewable and renewable resources (Clark and Munro, 1975; Hotelling, 1931; Schulze, 1974). More precisely, the optimal sand extraction path (or development), has an interdependency with fish stocks and their habitat which should be determined in order to maximize a social welfare by identifying how much fishery resources are adversely affected from sand development (Mueller, 1983; Swallow, 1994).

\subsection{Linkage between sand mining and fishery}

With interdependent damages on fishery population from marine sand mining, the $j$-th fishery stock size, $X_{t}^{j}$ is a function of the current catch rate, $H_{t}^{j}$, and marine sand mining impacts on the population, $I_{t}^{j}$ :

$$
X_{t+1}^{j}=X_{t}^{j}\left(1-M^{\jmath}\right)+R_{t}^{j}-H_{t}^{j}-I_{t}^{j}
$$

where $X_{t}^{j}$ is the biomass of $j$-th species at time $t, M_{t}^{j}$ is a natural mortality of $j$-th species, and $R_{t}^{j}$ is recruitment to the $j$-th species at time $t$.

It is assumed that the impact factor of marine sand mining has a proportional relationship with a quantity of marine sand extracted for simplicity. Thus, $I_{t}^{j}$ is a function of the sand quantity, $Q_{t}$ and the mining impact parameter, $\alpha\left(X_{t}^{j}, R_{t}^{j}\right)$, which is a function of biomass and recruitment at time $t$, and has the properties:

$I_{t}^{j}=\alpha\left(X_{t}^{j}, R_{t}^{j}\right) Q_{t}$ with $\frac{\partial \alpha(\bullet)}{\partial X_{t}^{j}}>0$ and $\frac{\partial \alpha(\bullet)}{\partial R_{t}^{j}}$.

Thus, the mining impact will increase as the mining operators extract more with a given biomass, $\frac{\partial I_{i}^{j}}{\partial Q_{t}^{j}}>0$. 
The catch rate $H_{t}^{j}$ at time t of the $j$-th species is given by general linear function:

$$
H_{t}^{j}=q^{j} E_{t}^{j} X_{t}^{j}
$$

here $q^{j}$ is the catchability coefficient of $j$-th species and $E_{t}^{j}$ is the effort level of the $j$-th fishy at time $t$. With the Beverton-Holt age-class model by Ricker (1975), the level of catch can be converted as:

$$
H_{t}^{j}=\sum_{i=k}^{i^{\max }} F_{i}^{j} N^{j}\left(i_{R}\right) W_{i}^{j} \prod_{i=i_{R}}^{i}\left(1-F_{i}^{j}\right)\left(1-M_{i}^{j}\right) \quad \text { for }\left(i_{R} \leq k \leq i_{\max }\right)
$$

where $W_{i}^{j}$ is weight at age $i, F_{i}^{j}$ is the fishing mortality rate, and age class $i_{R}$ and $i_{\max }$ are recruitment age and the maximum age for the species, respectively.

The application of age-structure models for multiple-species fisheries can be problematic because it is relatively difficult to obtain adequate age-structured data, particularly life-history parameters for every affected species (Bonfil, 2004). If data are available, the cohort model can track the life of individual age classes of fish through the whole life span (Pascoe, 1995). In the sand mining analysis, using the Beverton-Holt model is consistent with earlier findings for estimating the external costs of marine sand mining. Beyond consistency with earlier modeling, adopting a cohort model allows for consideration of the time-variant (dynamic) marginal external costs (MEC) to commercial fisheries, rather than a fixed MEC used in the previous study (Kim et al., 2008).

Thus, the stock size Eq. (1) can be re-written as the following Beverton-Holt age class model:

$$
\begin{aligned}
& X_{t+1}^{j}=X_{t}^{j}\left(1-M^{j}\right)+R_{t}^{j}-H_{t}^{j}-\alpha\left(X_{t}^{j}, R_{t}^{j}\right) Q_{t} \\
& =\sum_{i=k}^{i_{\max }} N^{j}\left(i_{R}\right) W_{i}{ }^{j} \prod_{i=i_{R}}^{i}\left(1-F_{i}{ }^{j}\right)\left(1-M_{i}{ }^{j}\right)-\alpha\left(X_{t}{ }^{j}, R_{t}{ }^{j}\right) Q_{t}
\end{aligned}
$$

for $\left(i_{R} \leq k \leq i_{\max }\right)$.

In this level of stock, the biomass of individuals in some age class $i\left(i>i_{R}\right)$ contains two components in Eq. (5):

$$
\sum_{i=k}^{i^{\max }} N^{j}\left(i_{R}\right) W_{i}{ }^{j}=X_{t}^{j}+R_{t}^{j} \quad \text { for } \quad\left(i_{R} \leq k \leq i_{\max }\right) .
$$

During the mining periods, the fishery industries will suffer from a decline of the current fishery population and the lost catch rate because of the higher mortality rate (100\%) and the disturbed bottom habitat with a positive impact, $I_{i}^{j}>0$ and $Q_{t}>0$. This is the short-term effect. After stopping mining, the excavated bottom starts to fill in, which allows the bottom habitat to recover to its pre-mining condition, approximately three years after ceases (Kim and Grigalunas, 2009; Kim et al., 2008). Next, once habitat recovery begins, there is a population recovery time period of each species reaching the pre-mining population level. This is the long-term effects that are economic damages from a foregone lost catches during total physical filling and biological population recovery period. Finally, indirect lost catch due to ecosystem (food web) effects also may occur if mining causes mortality to lower trophic organisms consumed by off-site species eventually harvested by commercial fishermen (Grigalunas et al., 2001; Kim and Grigalunas, 2009; Kim et al., 2008). I assume the lost catch of predator species in off-site is equal to $50 \%$ of the biomass in the mining area due to prey lost (i.e. I assume the homogeneity of biota in areas adjacent to the mining area). This food web effect also last for the same recovery period with long-term effect (Kim and Grigalunas, 2009; Kim et al., 2008).

Total economic value of the bottom habitat can be referred to as the economic loss occurred from absence of the habitat-supporting trophic organisms and fish species. Thus, the productivity value of the habitat can be determined by adding long-term and indirect damages.

\subsection{Social Optimum}

The discrete joint management model for marine sand and commercial fishery, which maximizes the social net benefit over both mining operators and the fishery industry simultaneously, is expressed by the following:

$$
M a x \_\pi=\left[\sum_{t=1}^{T} \frac{1}{(1+r)^{t}} B\left(n Q_{t}\right)-n C_{t}^{b} Q_{t}+\sum_{t=1}^{T} \frac{1}{(1+r)^{t}} \sum_{j=1}^{J} P_{t}^{j} H_{t}^{j}-C_{t}^{j} E_{t}^{j}\right]
$$

$$
\begin{aligned}
& \text { s.t. }\left[\begin{array}{l}
X_{t+1}^{1} \\
X_{t+1}^{2} \\
\vdots \\
X_{t+1}^{j}
\end{array}\right]=\left[\begin{array}{l}
X_{t}^{1}\left(1-M^{1}\right)+R_{t}^{1}-H_{t}^{1}-\alpha\left(X_{t}^{1}, R_{t}^{1}\right) Q_{t} \\
X_{t}{ }^{2}\left(1-M^{2}\right)+R_{t}{ }^{2}-H_{t}{ }^{2}-\alpha\left(X_{t}{ }^{2}, R_{t}{ }^{2}\right) Q_{t} \\
\vdots \\
X_{t}{ }^{j}\left(1-M^{j}\right)+R_{t}{ }^{j}-H_{t}{ }^{j}-\alpha\left(X_{t}{ }^{j}, R_{t}{ }^{j}\right) Q_{t}
\end{array}\right] \\
& =\left[\begin{array}{l}
\sum_{i=k}^{i^{\max }} N^{1}\left(i_{R}\right) W_{i}{ }_{i} \prod_{i=i_{R}}^{i}\left(1-F_{i}{ }^{1}\right)\left(1-M_{i}{ }_{i}^{1}\right)-\alpha\left(X_{t}{ }_{t}, R_{t}{ }^{1}\right) Q_{t} \\
\sum_{i=k}^{i^{\max }} N^{2}\left(i_{R}\right) W_{i}{ }^{2} \prod_{i=i_{R}}^{i}\left(1-F_{i}{ }^{2}\right)\left(1-M_{i}{ }^{2}\right)-\alpha\left(X_{t}{ }^{2}, R_{t}{ }^{2}\right) Q_{t} \\
\vdots \\
\sum_{i=k}^{i^{\max }} N^{j}\left(i_{R}\right) W_{i}{ }^{j} \prod_{i=i_{R}}^{i}\left(1-F_{i}{ }^{j}\right)\left(1-M_{i}{ }^{j}\right)-\alpha\left(X_{t}{ }^{j}, R_{t}{ }^{j}\right) Q_{t}
\end{array}\right]
\end{aligned}
$$$$
\text { for } \quad\left(i_{R} \leq k \leq i_{\max }\right) \text { and for }(\mathrm{t}=1, \quad \cdots, \quad \mathrm{T}-1), \quad \mathrm{S}(0)=\mathrm{S}_{0}
$$ 
$B_{t} \geq H_{t} \geq 0, X(0)=X_{0}, 0 \leq E_{t} \leq E_{\max }$, and $0 \leq \alpha(\bullet) \leq 1$

For mining operators, I assume that there are $n$-identical firms in the mining industry and the social optimum exploitation of given sand resources can be obtained by maximizing the net-present value(NPV) of net benefits to society: $Q_{t}$ is the quantity of sand extracted at time $\mathrm{t}$ by each of $\mathrm{n}$ identical firms, $B\left(n Q_{t}\right)$ is a gross social benefit of mining, which is obtained by integrating the negative sloping inverse demand curve of a fixed quantity of the total stock of the sand resources available, $\mathrm{S}_{0}, C_{t}^{s}$ is a marginal extraction cost of marine sand resources at time $t$, and $r$ is the social discount rate.

For fishery industries, the fishermen also maximize their $\mathrm{NPV}$, which is total revenue of catch, $\left(H_{t}^{i}\right.$ multiplied by the constant price, $\left.P_{t}^{j}\right)$ minus total fishing costs $\left(C_{t}^{j} E_{t}^{j}\right)$ of effort level, $E_{t}^{j}$ with a unit cost of effort, $C_{t}^{j}$.

In Eq. (7), though, the mining industry ${ }^{1)}$ wants to maximize their NPV over time, but the extraction quantities are constrained by the fishery stock effects. On the other hand, the fishing industry seeks to earn the highest return from harvesting, but lost catch due to the dredging diminishes fishery profits while sand mining persists. In fact, the fishing industry will suffer a loss in catch until the biological recovery level of fishery stocks which can be years after mining ceases (Kim et al., 2008).

\subsection{Three Estimation Cases Considered}

To estimate efficient management plans for both mining and fishery industry, I considered following three cases (Table 1). The first case is the "basic model." It is an unrealistic model because two industries maximize their own discounted profits independently assuming no damages to the fishery. In the second case, I consider an inefficient model in which the mining industry still maximizes their profits independently, but fishery industry has some positive damages (Upton and Sutinen, 2005). Since there are externalities from marine sand mining, it is needed to estimate the total damages on the commercial fishery if mining operators extract marine sand, ignoring their adverse effects on the fishery.

Hence, this second case internalizes externalities but does not consider joint management of the resources. The last case explicitly models joint management and hence is an efficient management model. In this model, both industries maximize their profits jointly considering mining impacts on the fishery. Although, there are damages to the fishery, mining operators include damages over time in their optimal mining decisions to maximize total net benefits for both industries by altering their original extraction plans. All three cases are simulated using General Algebraic Modeling System (GAMS) program.

\section{Data and Key variables}

As explained above, the developed joint management model is applied to the blue crab fishery as a representative affected species in marine sand mining case study in Ongjin District, Korea. Thus the blue crab is selected as the target exposed species because it is a bottom (and hence vulnerable) species and also the highest valuable species $(64 \%$ of total commercial landing in Ongjin District). The economic damages due to lost catch are also by far the highest among all of affected species, $96 \%$ of economic loss in an earlier article (Kim et al., 2008). Also, blue crab is the only species for which adequate biological data is available for the joint management model.

Table 1 Management Models Considered

\begin{tabular}{|c|c|c|}
\hline & $\begin{array}{c}\text { NPV } \\
\text { Maximization Rule }\end{array}$ & $\begin{array}{c}\text { Assumption on } \\
\text { Externality }\end{array}$ \\
\hline $\begin{array}{c}\text { Case I: Basic } \\
\text { Model }\end{array}$ & Independent & No Damages \\
\hline $\begin{array}{c}\text { Case II: Inefficient } \\
\text { Model }\end{array}$ & Independent & $\begin{array}{c}\text { Positive } \\
\text { Damages }\end{array}$ \\
\hline $\begin{array}{c}\text { Case III: Joint } \\
\text { Management Model }\end{array}$ & Jointly & $\begin{array}{c}\text { Positive } \\
\text { Damages }\end{array}$ \\
\hline
\end{tabular}

\subsection{Biological Data of the Blue Crab}

The Yeonpeong fishing ground is the richest spawning and catch area of the blue crab in Ongjin District, of which a total area is $750 \mathrm{~km}^{2}$ (Fig. 1). In total fishing ground of Ongjin District $\left(5,614 \mathrm{~km}^{2}\right)$, about $99.9 \%$ of the catch rate of crustacean including the blue crab is caught in just four fishing grounds encompassing 3,557km² (e.g. Yeonpeong, Mandori, Chochi, and General grounds in Fig. 1).

The stock size of the blue crab in 2001 is calculated using the catch rate of the Ongjin District relative to rate

1) As of the year 2005, there were 20 mining firms in Ongjin District. Each firm had 2 or 3 mining vessels, which were almost similar size with average $1,800 \mathrm{~m} 3$ capacity vessels. So it is reasonable to assume there are $\mathrm{n}$-identical firms in the Ongjin mining industry, Korea. 
for Incheon because currently, it is not possible to attain the biomass data of Ongjin District, Korea. Hence the statistical data for the catch rate of the crab fishery is available in Incheon by species and by types of gears, not in Ongjin District. Son and others of NFRDI(2004) estimated the weighted average recruitment number of the blue crab in the Yeonpeong fishing ground as 6,680,936.

Again, the recruitment and stock size of the blue crab in the Ongjin District were estimated relatively to the Yeonpeong fishing ground data in year 2001, which is the "Base Year" of the model analysis in this article (Table 2). The life history parameters of the blue crab for applying Beverton-Holt model were obtained from National Fisheries Research and Development Institute (2004), which were used in authors' previous study ( Kim et al., 2008) for estimating the damage from lost catch (Table 2).

Table 2 Stock size and life history parameters for blue crab in Ongjin district

\begin{tabular}{|cc|ccc|cc|}
\hline \multicolumn{2}{|c|}{ Mortality(\%) } & \multicolumn{2}{|c|}{ Length } & \multicolumn{2}{c|}{ vs Age } & \multicolumn{2}{c|}{ Weight vs Length } \\
\hline \multicolumn{2}{|c|}{$\mathrm{F}$} & $\mathrm{M} \infty(\mathrm{cm})$ & $\mathrm{K}$ & $\mathrm{t}_{0}$ & $\mathrm{a}$ & $\mathrm{b}$ \\
\hline 56.0 & 41.0 & 17.8 & 0.78 & -0.622 & 0.154 & 2.877 \\
\hline No. of Recruitment & \multicolumn{2}{|c|}{ Stock Size (MT) } & $\mathrm{t}_{\mathrm{R}}$ & \multicolumn{2}{|c|}{ Life } & Span \\
\hline \multicolumn{2}{|c|}{ 19,410,021 } & \multicolumn{2}{|c|}{10,651} & 0.3 & \multicolumn{2}{|c|}{3} \\
\hline
\end{tabular}

\subsection{Gill Net Fishing Industry for Blue Crab}

At the beginning of 1990's, the majority of blue crab was caught by a large pair bottom trawl. More recently (2000 2005), however, the gill net fishery catch has been the dominant technology in Ongjin District, $74 \%$ of all blue crab fishing fleets (MOMAF, 2007). According to the catch rate data, gill nets remain the most important technology for harvesting the blue crab. So I assume that blue crab fisheries are produced from a gill net fleet in this case.

Sixty one gill net fishing boats work the Yeongpeong fishing ground (NFRDI, 2004). Based on the relative percentage of the catch between Ongjin and Yeonpeong, an estimated 177 fishing boats operate in the Ongjin District. Thus, the fishing effort $(E)$ for the blue crab is the annual number of vessels estimated by the annual number of days at sea. The catch per unit of effort (CPUE) used in this study is calculated as the annual catch per vessel (stated in $\mathrm{kg} / \mathrm{vessel}$ ) (Table 3). Again, the number of fishing boats as an effort level is assumed to be a fixed over time because the blue crab is one of species under TAC management system and the government also uses the input control policy (e.g. restricting a number of boats) to manage the stock size (Ryu et al., 2005). The annual cost per gill net vessel was obtained from MOMAF (2006). The Ongjin Fishery Cooperative provided data on the weighted average price of the blue crab in the Ongjin District. The total annual fishing costs of one gill net vessel are $\$ 58,448.6$ (Table 4). In the model, the effort level is the number of vessels used for catching the blue crab per year, so the total cost is the unit cost of effort.

Table 3 Catch per unit of effort (CPUE) of gill net fishery in Ongjin district

\begin{tabular}{|c|c|c|}
\hline & Ongjin District ${ }^{*}$ & Yeonpeong Ground \\
\hline No. of Vessel & 177 & 61 \\
\hline CPUE (kg/vessel) & $33,655.7$ & $33,655.7$ \\
\hline
\end{tabular}

Source: NFRDI, 2004.

Note: * It is estimated from Yeonpeong Ground.

The most recent 5 years (2001 2005) landing prices of the blue crab provided by Ongjin Cooperation are used (Table 5). In light of the variation of annual catch between years, the weighted average landing price used and the price is converted in 2001 dollar values for the Base year of the analysis (Kim et al., 2008). Thus, the dockside price of the blue crab used in this study is $\$ 16.0$ per $\mathrm{kg}$.

Table 4 Fishing costs of gill net vessel for the blue crab (in 2001 dollars)

\begin{tabular}{|c|c|r|}
\hline Content of Fishing Costs & Item & Cost $(\$)$ \\
\hline & Fishing Gear & $7,497.5$ \\
& Fuel & $11,407.2$ \\
& Containers & 466.0 \\
Costs of fishing & Storage & 878.7 \\
& Consumption goods & $1,439.3$ \\
& Food and Drink & $2,134.9$ \\
& Well-being & 427.3 \\
Wages and Management & Repair & $2,474.0$ \\
Costs & Others & $1,340.5$ \\
& Sub-total & $28,065.3$ \\
& & $30,423.3$ \\
\hline \multicolumn{2}{|c|}{ Total Costs } & $58,488.6$ \\
\hline
\end{tabular}

Source: MOMAF (2006).

Table 5 Weighted average price of the blue crab in Ongjin district in 2001 dollar

(Unit: $\$ / \mathrm{kg}$ )

\begin{tabular}{|c|c|c|c|c|c|c|}
\hline Year & 2005 & 2004 & 2003 & 2002 & 2001 & Average \\
\hline Price & $\$ 14.8$ & $\$ 20.8$ & $\$ 13.8$ & $\$ 15.0$ & $\$ 15.4$ & $\$ 16.0$ \\
\hline
\end{tabular}


To examine the effects on the commercial fishery and its habitat from marine sand mining, I assume that: 1) food and habitat are biologically limited for all living species in the mining area, so that small changes in bottom habitat will cause stock size changes for fishery species; 2) very small changes in the biomass of the affected fisheries due to small impacts on the habitat will not cause effort level or harvest cost changes; 3) the affected fishery industries are small enough such that they have no price control power, i.e., they are price-takers.

\subsection{Marine Sand Industry}

Cumulative quantity of marine sand extracted in Ongjin District is about 134.7 million cubic meters from 1993 to 2001. So, in 2001, the current reserve amount of marine sand, is estimated to $857.8 \mathrm{M} \mathrm{m}^{3}$ with the 2meters allowable mining depth by law in Korea (Korea Aggregate Association, 2002).

Using a hydraulic dredge on a tug-assisted barge, the mining operation comprises departure to the permitted sties, dredging marine sand, back to the harbor after finishing mining, and discharging and cleaning sand (Cho and Chang, 2003; Kim, 2009; Korea Aggregate Association, 2002). With this information, the unit extraction cost,in Eq (7) is estimated as $\$ 3.79$ per unit of sand extracted $\left(\mathrm{m}^{3}\right)^{2)}$.

Finally, for simplicity, the negative sloping quasidemand for marine sand is regressed with 5 years (2001 2005) time series price and quantity of marine sand data in Korea, which is only available data at the current point: $P\left(Q_{t}\right)=A+B Q_{t}$ with $\mathrm{A}>0$ and $\mathrm{B}<0^{3)}$.

\subsection{Impact parameter estimation}

In the joint management model, I do not impose a constant per unit external cost on the mining operators. Instead, the quantities of extraction will be constrained by fishery stock impacts. Thus, the dredging activities reduce the current biomass of the blue crab, and the recruitment numbers in next period. The social planner maximizes the total social profit, NPV of the mining operators plus NPV of fishery industry, and the optimal extraction quantities of marine sand and harvest rate of the blue crab are determined interdependently.

For consistency with the estimates of economic damages on commercial fishery in the earlier study (Kim and Grigalunas, 2009; Kim et al., 2008;) with Beverton-Holt age-structure model (Ricker, 1975), the mining impacts on the blue crab, in Eq. (2) can be expressed in terms of excess mortality from the dredging;

$$
\begin{aligned}
& E_{-} \operatorname{Mort}_{t}^{i}=\phi_{t}(i) \times Q_{t} \text { and, } \\
& \alpha\left(X_{t}, R_{t}\right) Q_{t}=\sum_{i=k}^{i^{\max }} F_{i} N \quad\left(i_{R}\right) W_{i} \times E_{-} \text {Mort }_{t}^{i}
\end{aligned}
$$

where $E_{-}$Mort $_{t}^{i}$ is the excess mortality from the sand mining on the $i^{-t h}$ age at time $\mathrm{t}$, and $\phi_{t}(i)$ is the coefficient of the excess mortality at time $t$. With a consistency, the mortality coefficient, $\phi_{t}(i)$ is estimated assuming 100\% mortality in one unit area. Thus, every 2 million cubic meter of sand extraction in one mining area with $2 \mathrm{~m}$ depths $\quad\left(1000 m \times 1000 m \times 2 m=2,000,000 m^{3}\right) \quad$ kills all current biomass as well as recruitment of the affected blue crab in the mined area.

Here, some assumptions are necessary for illustrative empirical results to apply the theoretical joint management model. The recruitment amount of the blue crab is assumed to be the same every year $(10,610.1$ MT) in Ongjin District (Table 3). Hence, recruitment is stock independent.

\section{Results and Discussion}

The illustrative results show that the extraction of marine sand affects the harvest rate of the blue crab fishing industry over time (Fig. 2). With the interdependency between marine mining and the stock of the blue crab, the mining industry reduces the extraction quantity to minimize the adverse effects on blue crab fishery and to maximize the total social net benefit at the beginning of mining period (Table 6 ). Then the extraction quantities of the efficient joint management plan are relatively larger than the inefficient plan ignoring the

2) The extraction cost would be a function of distance from harbor and of the remaining marine sand reserve (extraction cost rises as the dredging depth increases). However, the permitted mining areas are not much different from each other and the dredging depth by law is fixed with $2 \mathrm{~m}$ law (Kim et al., 2008). So, the constant unit extraction cost is reasonable in this article.

3) The estimated parameters $\mathrm{A}$ and $\mathrm{B}$ in the quasi-demand function are 11485.58 and 0.274 respectively. To estimate theses parameters, the 5-years' annual sand prices are converted into a real price in year 2001 using Producer Price Index (PPI) to avoid auto-correlation problem due to inflationary effects. So the estimated Durbin-Watson d statistic, 1.575 indicates that there is no first-order autocorrelation. Although there are only five observations, the estimated parameters are significant at 5\% ( $\mathrm{p}=0.05)$ (see Kim (2009) for a detail of estimation) 
linkage between the mining and blue crab fishery. Since the resource rent of marine sand underground increase as the mining time goes relative to blue crab fishery value, the mining operators cannot postpone extracting one more unit of sand tomorrow to maximize total social NPV (Hartwick and Olewiler, 1998).

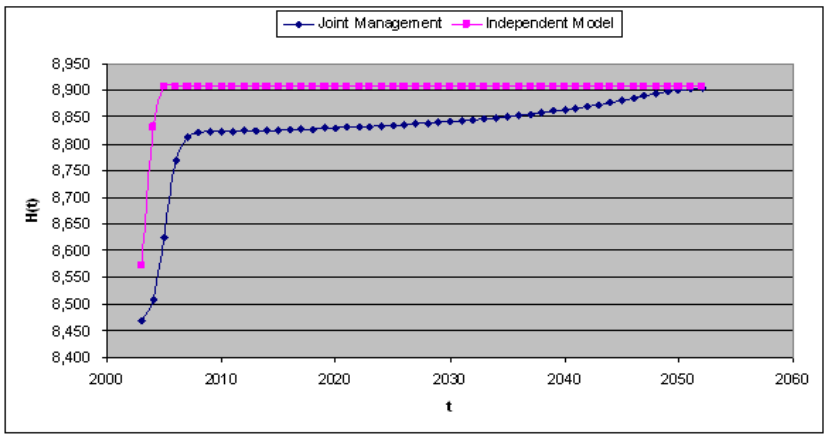

Fig. 2 Trajectories of the steady-state harvest equilibrium of the blue crab under different management plans

Also, fishery catch declines over time as a result of the external costs imposed by sand mining as depicted in Fig. 2. Without any impacts from mining activities, the blue crab fishery can achieve the equilibrium level (8,906 metric ton) of harvest quickly, in 2005. During the mining period (for 46 years), however, the catch rates under the efficient joint management plan have always been lower than with the inefficient plan. Moreover, the steady-state harvest level will be reached in 2052, which is six years after mining ceases because of the recovery time of the bottom habitat.

Finally, the external costs from marine sand mining lead to economic losses in the blue crab fishery of $\$ 22.5$ million over the affected period (Table 7). As shown in Fig. 2, the economic damages from lost catch due to the mining are the difference between the two harvest rates and change over time, depending on current stock size. This means that the external costs on the fishery resources are time-variant (or dynamic), not fixed. The mean dynamic external cost (DEC) is $\$ 0.022$ per cubic meter of sand and the maximum and minimum DECs are $\$ 0.153 / \mathrm{m}^{3}$ and $\$ 0.006 / \mathrm{m}^{3}$, respectively.

I note here that the estimated DEC underestimates the true environmental damages on the commercial fisheries because this article takes into account blue crab only. So the lager DEC should induce a somewhat different efficient management plan for both marine sand and commercial fishery resources: a longer extraction period of marine sand with a larger DEC.
Table 6 Comparison of joint extraction plan with independent plan

(Unit: $1000 \mathrm{~m}^{3}$ )

\begin{tabular}{|c|c|c|c|c|c|c|c|}
\hline \multirow{2}{*}{ Year } & \multirow{2}{*}{$\begin{array}{c}\text { Independe } \\
\text { nt (A) }\end{array}$} & $\begin{array}{c}\text { Quantity } \\
(\mathrm{B})\end{array}$ & $\begin{array}{c}\Delta \mathrm{Q} \\
(\mathrm{A}-\mathrm{B})\end{array}$ & Year & \multirow{2}{*}{$\begin{array}{c}\text { Independ } \\
\text { ent (A) }\end{array}$} & $\begin{array}{c}\text { Quantity } \\
(\mathrm{B})\end{array}$ & $\begin{array}{c}\Delta \mathrm{Q} \\
(\mathrm{A}-\mathrm{B})\end{array}$ \\
\hline 2001 & 26,334 & 25,461 & 873 & 2024 & 20,946 & 20,959 & -13 \\
\hline 2002 & 26,224 & 25,321 & 903 & 2025 & 20,496 & 20,520 & -24 \\
\hline 2003 & 26,107 & 25,229 & 878 & 2026 & 20,018 & 20,053 & -35 \\
\hline 2004 & 25,982 & 25,368 & 614 & 2027 & 19,510 & 19,556 & -46 \\
\hline 2005 & 25,849 & 25,530 & 319 & 2028 & 18,970 & 19,029 & -59 \\
\hline 2006 & 25,709 & 25,611 & 98 & 2029 & 18,395 & 18,468 & -73 \\
\hline 2007 & 25,559 & 25,464 & 95 & 2030 & 17,785 & 17,871 & -86 \\
\hline 2008 & 25,400 & 25,309 & 91 & 2031 & 17,136 & 17,237 & -101 \\
\hline 2009 & 25,230 & 25,144 & 86 & 2032 & 16,446 & 16,564 & -118 \\
\hline 2010 & 25,050 & 24,968 & 82 & 2033 & 15,713 & 15,847 & -134 \\
\hline 2011 & 24,859 & 24,781 & 78 & 2034 & 14,933 & 15,086 & -153 \\
\hline 2012 & 24,656 & 24,583 & 73 & 2035 & 14,105 & 14,277 & -172 \\
\hline 2013 & 24,440 & 24,371 & 69 & 2036 & 13,224 & 13,416 & -192 \\
\hline 2014 & 24,210 & 24,147 & 63 & 2037 & 12,288 & 12,502 & -214 \\
\hline 2015 & 23,966 & 23,909 & 57 & 2038 & 11,292 & 11,530 & -238 \\
\hline 2016 & 23,706 & 23,655 & 51 & 2039 & 10,234 & 10,496 & -262 \\
\hline 2017 & 23,431 & 23,386 & 45 & 2040 & 9,110 & 9,398 & -288 \\
\hline 2018 & 23,137 & 23,099 & 38 & 2041 & 7,914 & 8,230 & -316 \\
\hline 2019 & 22,826 & 22,795 & 31 & 2042 & 6,643 & 6,989 & -346 \\
\hline 2020 & 22,494 & 22,471 & 23 & 2043 & 5,293 & 5,670 & -377 \\
\hline 2021 & 22,142 & 22,127 & 15 & 2044 & 3,857 & 4,267 & -411 \\
\hline 2022 & 21,767 & 21,761 & 6 & 2045 & 2,330 & 2,776 & -446 \\
\hline 2023 & 21,369 & 21,372 & -3 & 2046 & 706 & 1,187 & -482 \\
\hline & & & & Total & 857,790 & 857,790 & - \\
\hline & & & & & & & \\
\hline
\end{tabular}

From total external costs, I estimated the foregone economic benefits of bottom habitat because of the reduction of the commercial fishery productivity. Since the bottom habitat or ecosystem supports on-site tropic organisms and prey species, harmed or disturbed habitats result in a reduction in food supply for predator species, which are the commercial catchable species on-site as well as at adjacent off-sites. So, the total foregone benefits of bottom habitat for blue crab fishery are the summation of all lost catch until the injured habitat recovers the pre-mining condition. The estimated mean economic value of bottom habitat for blue crab is $\$ 0.031$ per square area $\left(\mathrm{km}^{2}\right)$, and the largest value of the habitat is $\$ 0.273 / \mathrm{km}^{2}$. These estimates represent the asset value of bottom habitat as an input for blue crab productivity (Barbier, 2007; Upton and Sutinen, 2005).

Lastly, I compare the net-present values of three models to examine validity of joint management model for society. For the basic model, total profits of sand mining industry are $\$ 1.492$ billion and blue crab industry earns $\$ 1.9$ billion with zero external cost assumption (Table 7). 
Next, because the inefficient model assumes that the mining industry maximizes their profits independently like the basic model, the profits are same with basic model ( $\$ 1.492$ billion). But there are damages to the blue crab fishery, so total profits of blue crab are $\$ 1.82$ billion, which is $\$ 86.7$ million less than the basic model. This $\$ 86.7$ million is the external costs to blue crab fishery for all affected period (Table 7).

In the joint-management model, both mining and blue crab industries take into account the interdependent linkage. They maximize overall profits by minimizing damages on blue crab fishery. The external costs are reduced to \$22.5 million comparing with the external costs (\$86.7 million) with inefficient extraction model. Since the mining industry changes their extraction plan corresponding to minimize the impacts on blue crab fishery, they have less profit (about $\$ 1.5$ billion), but the joint management model gives the larger total net gain, $\$ 63.9$ million to society (Table 7). Hence, the illustrative empirical results suggest that if resource uses are to be maximized, the interdependency among marine resources should be considered to determine the efficient extraction quantities of marine sand resource and efficient harvest rates of blue crab fishery over time.

Table 7 Social economic damage estimates under inefficient management plan of marine sand and blue crab fishery resources (Unit: million dollars)

\begin{tabular}{|c|c|c|c|c|}
\hline Case & $\begin{array}{c}\text { Mining } \\
\text { Industry } \\
\text { (46 years) }\end{array}$ & $\begin{array}{c}\text { Blue Crab } \\
\text { Industry } \\
(52 \text { years })\end{array}$ & $\begin{array}{c}\text { Externa } \\
1 \text { Costs }\end{array}$ & Total NPV \\
\hline Basic Model & $\$ 1,492.0$ & $\$ 1,904.8$ & $\$ 0$ & - \\
\hline $\begin{array}{c}\text { Inefficient Model } \\
\text { Joint Management } \\
\text { Model }\end{array}$ & $\$ 1,492.0$ & $\$ 1,818.1$ & $\$ 86.7$ & $\$ 3,310.1$ \\
\hline
\end{tabular}

\section{Conclusions}

Development of marine nonrenewable resources when renewable fishery resources are adversely interrelated can be very important. However, it is difficult to estimate this linkage because of the problem of quantification of externalities on the affected fishery, particularly when resources externalities occur over time. In this study, trade-offs between marine sand resources development and preservation of the commercial fishery resources (here, blue crab fishery) in Korea because of environmental damages from marine mining activities were used as a case study.

Lacking information about mining-blue crab fishery linkages in Korea, a Hotelling-type management plans for exhaustible marine sand resources only cannot suggest the efficient extraction path of marine sand considering the environmental damages on the blue crab fishery and its habitat/ecosystem. Instead, I developed the joint management bioecomonic model for both resources. The developed model maximizes social benefits of two resource industries together. Thus, the model allows the interrelation between sand mining and fishery damages. This model extends previous studies for renewable and nonrenewable resource linkages.

The developed joint management extraction model was applied to Korea marine sand mining case in the Ongjin District. The illustrative empirical results suggest that if the social net benefits of nonrenewable sand resource uses are to be maximized, the changes in fishery stock size and bottom habitat from the mining activities should be considered to determine the efficient extraction paths of marine sand over time. The joint management model takes into account the interdependency between marine sand mining and the blue crab fishery and its habitat damage. The efficient development plans for marine sand are estimated recognizing the tradeoff with the preservation of blue crab fishery stock size. The dynamic fishery population constrains marine sand mining because damages to blue crab increase as marine sand mining increases. Thus, the developed model is a more rigorous theoretic approach, which incorporates dynamic environmental costs (or variable external costs), rather than a fixed external cost per unit.

In summary, the efficient extraction path of marine sand resources considering the interdependent linkages compares the extraction plan under inefficient management policy (independent extraction plan). The estimated social economic damages are $\$ 63.9$ million if the mining operators do not consider the economic external costs on blue crab fishery over the 52-year production period. Marine sand mining activities impose excess mortality on the current blue crab population and disturbed bottom habitats, which result in economic loss from declined productivity of blue crab fishery. The estimated harvest rate of blue crab of two management plans are compared with each other, and demonstrate that the efficient management plan can't achieve a steady-state equilibrium harvest level during the mining period and until the harmed habitats fully recover after ceasing the mining (Fig. 2). With this estimates, the 
stock size dependent dynamic external costs on blue crab assessed as $\$ 0.022 / \mathrm{m}^{3}$ in mean value and maximum $\$ 0.153 / \mathrm{m}^{3}$.

In addition, I estimate the economic value of the bottom habitats from total environmental costs from marine sand development. The estimated foregone benefits of the habitat for blue crab during recovery period amount average $\$ 0.031$ per square area $\left(\mathrm{km}^{2}\right)$.

Despite the limitation of my analysis for estimating true environmental costs on all affected fishery resources, I have shown that the considering a linkage between marine mineral resource and fishery and its ecosystem as a natural capital suggest a better resource management policy for a social economy. So the empirical results are interpreted with emphasis on guidelines for management policy for all kinds of marine mineral development cases.

\section{Acknowledgements}

This research was supported in part by the Korea Maritime University Research Fund in 2010 and the research grant from the Korea Maritime Institute (KMI) to the Korea-America Joint Marine Policy Research Center at University of Rhode Island. The author is grateful to Thomas Grigalunas and James Opaluch for useful discussion and helpful suggestions.

\section{References}

[1] Barbier, E. B.(2007), "Valuing ecosystem services as productive inputs“, Economic Policy Vol. 22, No. 49, pp. 177-229.

[2] Barbier, E. B., Strand, I., Sathirathai, S.,(2002), "Do open access conditions affect the valuation of an externality? Estimating the welfare effects of mangrove-fishery linkages“, Environmental and Resource Economics Vol. 21, No. 4, pp. 343-67.

[3] Bonfil, R.,(2004), "Fishery Stock Assessment Models and Their Application to Sharks", In J. A. Musick and R. Bonfil, Eds. Management Techniques for Elasmobranch Fisheries. FAO Fisheries Technical Paper No. 474: Rome, pp. 205-240.

[4] Cho, D. O.,(2006), "Challenges to sustainable development of marine sand in Korea“, Journal of Ocean \& Coastal Management Vol. 49, pp. 1-21.

[5] Cho, D.O., Chang, H. B.,(2003), A Study on the Status of Supply and Demand of Marine Sand and Management System. Research Project Report
No.2003-17, Korea Maritime Institute, p. 157.

[6] Clark, C.W., Munro G. R.,(1975), "The economics of fishing and modern capital theory: a simplified approach“, Journal of Environmental Economics and Management Vol. 2, No. 2, pp. 92-106.

[7] Freeman, A. M. III,(2003), Valuing Environmental and Natural Resource Services: Theory and Measurement, $2^{\text {nd }}$ ed. Washington, D.C.: Resources for the Future.

[8] Grigalunas, T., Opaluch, J. J., Luo, M.,(2001), "The Economic Costs to Fisheries from Marine Sediment Disposal: Case Study of Providence, RI, USA“, Ecological Economics Vol. 38, pp. 47-58.

[9] Hartwick, J. M., Olewiler, N. D., 1998. The Economics of Natural Resource Use, $2^{\text {nd }}$ ed. Addison-Wesley, p. 432.

[10] Hoel, M.,(1978), "Resource extraction and recycling with environmental costs", Journal of Environmental Economics and Management Vol. 5, pp. 220-235.

[11] Hotelling, H.,(1931), "The economics of exhaustible resources", Journal of Political Economy Vol. 39, No. 2, pp. 137-175.

[12] Kim, T. G.,(2009), "Efficient management of marine resources in conflict: An empirical study of marine sand mining, Korea”, Journal of Environmental Management Vol. 91, pp. 78-86.

[13] Kim, T. G., Grigalunas, T. A.,(2009), "Simulating Direct and Indirect Damages to Commercial Fisheries from Marine Sand Mining: A Case Study in Korea", Environmental Management Vol. 44, pp. 566-578.

[14] Kim, T. G., Grigalunas, T. A., Han, K. N.,(2008), “The Economic Costs to Fisheries Because of Marine Sand Mining in Ongjin, Korea: Concepts, Methods and Illustrative Results”, Ecological Economics Vol. 65, pp. 498-507.

[15] Korea Aggregates Association,(2002), A Study on Environmental Impact of Marine Sand Mining in Gyeonggi Province Bay and Assessment of Quantity of Resources, 2002. Incheon, Korea, p. 585.

[16] Korea, Republic of, Ministry of Maritime Affairs and Fisheries (MOMAF),(2003), Analysis on Investment Effects of the Korean Inshore and Offshore Vessel BuyBack Program, pp. 421-423.

[17] Korea, Republic of, Ministry of Maritime Affairs and Fisheries (MOMAF),(2006), Establishment of Countermeasures for Domestic Fishery Industries and Fishing Villages in accordance with Conclusion of WTO/FTA, p. 507.

[18] Korea, Republic of, Ministry of Maritime Affairs and 
Fisheries (MOMAF),(2007), Fishery Statistic Data, http://www.momaf.go.kr/info/statistics.

[19] Krautkraemer, J. A.,(1998), "Nonrenewable resource scarcity", Journal of Economic Literature Vol, XXXVI No. 4, pp. 2065-2107.

[20] Mueller, M. J.,(1983), “Optimal Ground water Depletion With Interdependent Nonrenewable and Renewable Resources", Water Resources Research Vol. 19, pp. 1091-1098.

[21] National Fisheries Research and Development Institute (NFRDI),(2000), The Ecology and fishing grounds of main fisheries resource in Exclusive Economic Zone (EEZ), p. 317.

[22] National Fisheries Research and Development Institute (NFRDI),(2004), Stock Assessment and Fishery Evaluation Report of Year 2005 TAC-based Fisheries Management in the Adjacent Korean Waters, p. 239.

[23] Pascoe, S.,(1995), Bioeconomic Models and Modeling: Theory and Practice, Centre for the Economics and Management of Aquatic Resources (ECMARE). Department of Economics, University of Portsmouth.

[24] Pindyck, R. S.,(1978), "The Optimal Exploration and Production of Nonrenewable Resources", Journal of Political Economy Vol. 86, pp. 841-861.

[25] Ricker, W. E.,(1975), "Computation and Interpretation of Biological Statistics of Fisheries Populations", Bulletin of the Fisheries Research Board of Canada Vol. 191, p. 382.

[26] Ryu, J., Gates, J. M., Nam, J. O.,(2005), A study on 10Assessment of TAC for Multi-species and Multi-gears: An Assessment of TAC for Multispecies and a Single-gear. Research Project Report No. 2005-25, Korea Maritime Institute, p. 161.

[27] Schulze, W. D.,(1974), "The Optimal Use of NonRenewable Resources: The Theory of Extraction", Journal of Environmental Economics and Management Vo. 1, pp. 53-73.

[28] Swallow, S. K.,(1990), "Depletion of the Environmental Basis for Renewable Resources: The Economics of Interdependent Renewable and Nonrenewable Resources", Journal of Environmental Economics and Management Vol. 19, pp. 281-296.

[29] Swallow, S. K.,(1994), "Renewable and Nonrenewable Resource Theory Applied to Coastal Agriculture, Forest, Wetland, and Fishery Linkages", Marine Resource Economics Vol. 9, pp. 291-310.

[30] Swallow, S. K.,(1996), "Resource Capital Theory and Ecosystem Economics: Developing Nonrenewable
Habitats with Heterogeneous Quality”, Southern Economic Journal Vol. 63, No. 1, pp. 106-123.

[31] Vita, G. D.,(2006), "Natural resources dynamics: Exhaustible and renewable resources, and the rate of technical substitution”, Resources Policy Vol. 31, pp. $172-182$.

[32] Upton, H. F., Sutinen, J. G.,(2005), Fish Habitats: A Valuable Ecosystem Asset. IN: Sustaining Large Marine Ecosystems: The Human Dimension, Elsevier, pp. 201-213.

Received 19 November 2012

Revised 11 December 2012

Accepted 11 December 2012 